Tropical Journal of Pharmaceutical Research February 2013; 12 (1): 85-91

ISSN: $1596-5996$ (print); 1596-9827 (electronic)

(c) Pharmacotherapy Group, Faculty of Pharmacy, University of Benin, Benin City, 300001 Nigeria.

All rights reserved.

Available online at http://www.tjpr.org

Original Research Article

http://dx.doi.org/10.4314/tjpr.v12i1.14

\title{
Anti-diarrhea and anti-oxidant properties of Magnolol
}

\author{
YL Pang ${ }^{1,2 \dagger}$, XF Han ${ }^{3 \dagger}$, MA Bamikole ${ }^{4}$, ZH Gong ${ }^{1}$, SX Tang ${ }^{3}$, ZL Tan ${ }^{3 *}$, WJ Xiao', \\ CS Zhou ${ }^{3}$, M Wang $^{3}$ and YL Deng ${ }^{1}$ \\ ${ }^{1}$ National Research Center of Engineering \& Technology for Utilization of Botanical Functional Ingredients, Hunan Agricultural \\ University, Changsha 410128, Hunan, , '2Guilin Tea Science Research Institute of Guangxi, Guilin 541004, Guangxi, ${ }^{3}$ Key \\ Laboratory of Agro-ecological Processes in Subtropical Region, Institute of Subtropical Agriculture, The Chinese Academy of \\ Sciences, Changsha 410125, Hunan ${ }^{4}$ Department of Animal Science, Faculty of Agriculture, University of Benin, PMB 1154, \\ Benin City, Nigeria.
}

^For correspondence: Email: zltan@isa.ac.cn, xiaowenjungong@163.com; Tel: 86-731-84619702; Fax: 86-731-84612685

Revised accepted: 25 November 2012

\begin{abstract}
Purpose: To provide an experimental basis for the anti-diarrheal and anti-oxidant properties of the bark extract of Magnolia officinalis Rehd. et Wils., a Chinese traditional herb called magnolol.

Methods: The effects of magnolol on castor oil-induced diarrhea, small intestinal transit (SIT) in mice were investigated. Additionally, the antioxidant activity of magnolol was assessed in mice by the following parameters: glutathione (GSH), total antioxidant capacity (T-AOC), antioxidant enzyme activities and their gene expression level.

Results: Compared with diarrhea model control group, magnolol (25, 50, or $100 \mathrm{mg} / \mathrm{kg}$ body weight) showed significant $(p<0.05)$ inhibitory activity against castor oil-induced diarrhea in mice. Administration of magnolol (25, 50, and $100 \mathrm{mg} / \mathrm{kg})$ also lowered neostigmine-induced SIT acceleration to $60.34 \pm 5.17,59.61 \pm 7.66$, and $54.12 \pm 7.27 \%$, respectively, as against $70.1 \pm 6.89 \%$ for neostigmine control group. In vivo antioxidant assay results showed that mice treated with magnolol exhibited significantly $(p<0.001)$ higher activities of catalase $(C A T)$, superoxide dismutase $(S O D)$, and glutathione peroxidase (GSH-PX) activities in blood, compared to control. Similarly, magnolol proups showed significantly higher CAT and SOD and T-AOC activities $(p<0.01)$ than control in liver tissues. The $100 \mathrm{mg} / \mathrm{kg}$ magnolol group had significantly higher liver GSH content than normal control group (1.01 vs. $0.79 \mathrm{mg} / \mathrm{mg}$ protein). At 25 and $50 \mathrm{mg} / \mathrm{kg}$ doses, magnolol significantly enhanced gene expression levels of CAT $(p<0.01)$ in liver.

Conclusion: Findings from this study indicate that magnolol possesses anti-diarrheal activity and is probably one of the main anti-diarrhea ingredients of Cortex Magnoliae Officinalis. Magnolol modulation of the activity and gene expression of antioxidant enzymes may therefore exert beneficial effects in antioxidant defense.
\end{abstract}

Keywords: Magnolol, Diarrhea, Small intestinal transit, Antioxidant enzyme, Gene expression

Tropical Journal of Pharmaceutical Research is indexed by Science Citation Index (SciSearch), Scopus, International Pharmaceutical Abstract, Chemical Abstracts, Embase, Index Copernicus, EBSCO, African Index Medicus, JournalSeek, Journal Citation Reports/Science Edition, Directory of Open Access Journals (DOAJ), African Journal Online, Bioline International, Open-J-Gate and Pharmacy Abstracts

\section{INTRODUCTION}

The plant, Magnolia officinalis Rehd. et Wils. also known as Magnolia/Houpu, of the family Magnoliacea, is one of the most popular traditional Chinese medicines. Its pharmaceutical properties are found in the bark and root [1]. The
Chinese name for the herb, 'houpu', refers to the thick (hou) bark that is the unadorned (pu) portion of the plant. The English name for medicinal materials of this plant is Cortex Magnoliae Officinalis (bark of Magnolia officinalis Rehd. et Wils.). This herb has been widely used in the treatment of diseases such as thrombotic 
stroke, typhoid fever, anxiety and nervous disturbance, diarrhea, cough and phlegm [2,3]. A major bioactive constituent of Cortex Magnoliae Officinalis is magnolol (Fig. 1).

Recent investigations have shown that magnolol possesses a wide range of physiological activities such as anti-tumor [4], anti-microbia [5], anti-clastogenic [6] and anti-platelet [7], .Moreover, while Cortex Magnoliae Officinalis has been used to treat diarrhea in traditional Chinese medicine, its anti-diarrhea active components are not defined and its mechanism of action is still not clear until now. Although some researchers have investigated the antioxidant activity of magnolol extracted from Cortex Magnoliae Officinalis [8], few of those studies were done in vivo. Therefore, the objective of this experiment was to investigate the anti-diarrhea property of magnolol using the castor oil-induced diarrhea mice model and small intestinal transit (SIT) and to determine the antioxidant activity of magnolol through examination of antioxidant enzyme responses at both enzymatic and transcript levels.

\section{EXPERIMENTAL}

\section{Animals}

The use of animals and the experimental procedure were approved (ref. no. AWCISA2010012) by the Animal Welfare Committee of the Institute of Subtropical Agriculture, Chinese Academy of Sciences, and the Guidelines for Good Practice in Laboratory Animals Feeding and Management was followed [9]. Male Kunming mice, 4 - 5 weeks old and weighing $20 \pm 2 \mathrm{~g}$, were obtained from Hunan SLAC Laboratory Animal Company. The animals were maintained under standard environmental conditions and had access to feed and water ad libitum.

\section{Plant material}

The plant material tested was the bark of Magnolia officinalis Rehd. et Wils. planted in Jianghua Yao Autonomous County, Hunan, China, in May 2009 at day time. The plant was identified by Professor ZH Liu, Department of Botany Resources, College of Horticulture and Gardening, Hunan Agricultural University, and a voucher specimen (Accession no. HNYD-09126) was deposited at the Specimen Center of Hunan Agricultural University, Changsha, Hunan, China. The crude extract was obtained from the bark using $60 \%$ ethanol and purified with HP-20 macroporous absorbing resin. The eluent containing magnolol was obtained by fraction collection, and the solvent was removed, by vacuum concentration, and magnolol obtained wby freeze-drying. The purity of the magnolol was measured by high performance liquid chromatography (HPLC). All doses of magnolol in this study were dissolved in $2 \% \mathrm{v} / \mathrm{v}$ aqueous Tween 80 solution for oral gavage administration.

\section{Tests for anti-diarrhea activity}

\section{Castor oil-induced diarrhea}

Mice fasted for $24 \mathrm{~h}$ were randomly divided into five groups of ten mice each, diarrhoea was induced by administering $0.4 \mathrm{ml}$ of castor oil orally to mice [10]. The positive control group was orally gavaged with loperamide hydrochloride (3 $\mathrm{mg} / \mathrm{kg}$ ), the model control group was orally administered saline $(20 \mathrm{ml} / \mathrm{kg})$, and magnolol-treated groups orally gavaged with varying doses of magnolol (25, 50 and 100 $\mathrm{mg} / \mathrm{kg}$ BW) $30 \mathrm{~min}$ before castor oil administration. Each animal was kept a separate cage with the floor covered with filter paper. The paper was changed every hour. Total number of stools, and the number and diameter of loose stools were observed within $6 \mathrm{~h}$ after administration of castor oil. The severity of diarrhea was assessed by loose stool incidence rate (LSIR), average loose stools grade (ALSG) and diarrhea index (DI) [11]. LSIR is the ratio of loose stools number to total stools number in each animal. Loose stools grade (LSG) describes the degree of loose stools pollution on the filter papers. The ALSG is the ratio of all loose stools grades to loose stools numbers in each mouse. Then DI is calculated by multiplying LSR by ALSG.

\section{Effect on small intestinal transit}

Healthy Kunming mice were randomly divided into five groups of ten mice each: the first three groups were administered magnolol orally at the doses of 25,50 and $100 \mathrm{ml} / \mathrm{kg}$, respectively; the other two groups were neostigmine group and normal (control) group, respectively, and both were administered saline $(20 \mathrm{ml} / \mathrm{kg})$. All the mice received magnolol or saline treatment by oral gavage once daily for 4 days. On day 4, 30 min after oral treatment (except for normal control group), all the groups received $0.15 \mathrm{mg} / \mathrm{kg}$ neostigmine by intraperitoneal (ip) injection. Twenty minutes later, $5 \%$ charcoal meal (10 $\mathrm{ml} / \mathrm{kg}$ ) was given to each mouse by intragastric gavage. After $20 \mathrm{~min}$, all the animals were sacrificed by cervical dislocation and the small intestines were isolated immediately. The distance travelled by the charcoal meal from the pylorus and the total length of the intestine were 
measured in $\mathrm{cm}$. Small intestinal transit (SIT) was expressed as the percent (\%) of the distance traveled by the charcoal meal relative to the total length of the small intestine [12].

\section{Tests for antioxidant activity}

\section{Animals and treatment}

Kunming male mice were randomly divided into five groups $(n=8)$ : blank control group treated with $2 \%$ aqueous Tween 80 solution, positive control group treated with $50 \mathrm{mg} / \mathrm{kg}$ vitamin $\mathrm{E}$ dissolved in $2 \%$ aqueous Tween 80 solution, three magnolol-treated groups administered 25, 50 or $100 \mathrm{mg} / \mathrm{kg}$ doses, respectively. All the animals were administered the respective doses via oral gavage once daily for 14 consecutive days.

On the 14th $d$ of oral administration, all mice were treated with light ether anesthesia. Thereafter, the blood was collected via retroorbital bleeding into heparin treated tubes to obtain blood plasma samples for analysis of antioxidant parameters. The mice were sacrificed by cervical dislocation after bleeding. The liver was rapidly removed under aseptic condition, and quick-frozen in liquid nitrogen pending further analysis.

\section{Chemical analysis}

The activity of glutathione peroxidase (GSH-Px), total superoxide dismutase (T-SOD) and catalase (CAT) in plasma and liver, as well as glutathione $(\mathrm{GSH})$ and total antioxidative capacity (T-AOC) in liver, were measured using commercially available kits (Jiancheng Biology Company., China).

\section{Gene expression analysis}

Total RNA from liver tissue was isolated using TRIzol reagent (Invitrogen, USA). Thereafter, cDNA synthesis from liver was performed with RevertAid First Strand cDNA Synthesis Kit (Fermentas, USA). Primers for CAT gene (forward primer CCGAGTCTCTCCATCAGGTTT C; reverse primer CGGTCTTGTAATGGAACTTG CA), GSH-Px gene (forward primer CTGGCAT TGGCTTGGTGAT; reverse primer GTGGAAAG GCATCGGGAAT), copper-zinc superoxide dismutase (Cu/Zn-SOD) gene (forward primer AAGCGGTGAACCAGTTGTGTT; reverse primer GGCCACCATGTTTCTTAGAGTGA), manganese superoxide dismutase (Mn-SOD) gene (forward primer CTGGAGGCTATCAAGCGT GACT; reverse primer CCTGATTAGAGCAG GCAGCAAT), extracellular superoxide dismutase (EC-SOD) gene (forward primer GTG GCTCTGTCACCATGTCAAAT; reverse primer CGTCCTAGCTCCATCCAGATCT) and $\beta$-actin gene (forward primer AGAGGGAAATCGTGC GTGAC; reverse primer CAATAGTGATGAC CTGGCCGT) were designed using Premier 5 software.

A $10 \mu \mathrm{l}$ reaction mixture containing $5 \mu \mathrm{L} 2 \times$ Power SYBR Green PCR Master Mix (Applied Biosystems, USA), $0.1 \mu \mathrm{L}$ cNDA template, $0.3 \mu \mathrm{L}$ forward primer $(1 \mu \mathrm{mol} / \mathrm{L}), 0.3 \mu \mathrm{L}$ reverse primer $(1 \mu \mathrm{mol} / \mathrm{L})$ and $4.3 \mu \mathrm{L}$ water, was conducted on an ABI 7900 HT fast real-time PCR system (Applied Biosystems, USA) using the following cycling conditions: $95^{\circ} \mathrm{C}$ for $10 \mathrm{~s}$ holding and 40 cycles of $95{ }^{\circ} \mathrm{C}$ for $20 \mathrm{~s}, 60{ }^{\circ} \mathrm{C}$ for $30 \mathrm{~s}$. Quantification of the PCR products of all samples was evaluated in comparison with the PCR product to $\beta$-actin. The relative changes of mRNA expression ratio determined from qPCR were calculated according to the $2^{\Delta \mathrm{CT}}$ method, where, $\triangle \mathrm{CT}=\mathrm{CT}$ samples $-\mathrm{CT} \beta$-actin

\section{Statistical analysis}

The data were expressed as mean $\pm S D$ and analyzed statistically using ANOVA, followed by Dunnett's comparisons test using SAS software (Version 8, SAS Institute Inc., Cary, NC, USA). Differences at $p<0.05$ were considered to be statistically significant, while $p<0.01$ and $p<$ 0.001 were considered to be highly significant.

\section{RESULTS}

\section{Extraction of magnolol}

The crude extraction rate of magnolol reached 86.8\% using ethanol extraction. After the purification with HP-20 macroporous absorbing resin, the purity of magnolol was $96.7 \%$ as indicated by HPLC analysis.

\section{Inhibitory effect of magnolol on castor-oil- induced diarrhea}

The results of LSR, ALST and DI are shown in Table 1. ALSG did not differ between model control, positive control and magnonol treatment groups. The LSR of model control mice was higher $(p<0.05)$ than that of magnolol groups, while LSR of positive control group was lower ( $p$ $<0.001$ ) than that of the latter. Model control group had significantly higher DI than magnolol treatment groups, while positive control group had the least DI. 
Table 1: Effect of magnolol on diarrhea induced by castor oil in mice

\begin{tabular}{lccc}
\hline Group & LSR & ALSG & DI \\
\hline Model control & $0.83 \pm 0.09$ & $1.67 \pm 0.13$ & $1.38 \pm 0.16$ \\
Positive control & $0.37 \pm 0.08$ & $1.67 \pm 0.12$ & $0.62 \pm 0.15$ \\
Magnolol $(25 \mathrm{mg} / \mathrm{ml})$ & $0.69 \pm 0.12^{\# \#^{\star \star \star}}$ & $1.64 \pm 0.10$ & $1.13 \pm 0.18^{\# \star \star \star}$ \\
Magnolol $(50 \mathrm{mg} / \mathrm{ml})$ & $0.72 \pm 0.08^{\# \star \star \star}$ & $1.60 \pm 0.16$ & $1.15 \pm 0.18^{\#^{\star \star \star}}$ \\
Magnolol $(100 \mathrm{mg} / \mathrm{ml})$ & $0.65 \pm 0.06^{\# \# \#^{* \star *}}$ & $1.66 \pm 0.11$ & $1.08 \pm 0.12^{\# \#^{* \star *}}$ \\
\hline
\end{tabular}

Model control = castor oil-induced-diarrhea model; Positive control: castor oil-induced-diarrhea model + loperamide hydrochloride administration; ${ }^{\#} p<0.05$, ${ }^{\# \#} p<0.01,{ }^{\# \# \#} p<0.001$, compared with model control; ${ }^{*} p<0.05,{ }^{* *} p<0.01,{ }^{* \star *} p<0.001$, compared with positive control group

Table 2: Effect of magnolol on small intestine transit of mice

\begin{tabular}{|c|c|c|c|}
\hline Group & $\begin{array}{c}\text { Small intestine length } \\
(\mathbf{c m})\end{array}$ & $\begin{array}{l}\text { Carbon promote distance } \\
(\mathbf{c m})\end{array}$ & $\begin{array}{c}\text { Small intestinal transit } \\
\text { (SIT) } \\
(\%)\end{array}$ \\
\hline Normal control & $51.8 \pm 5.65$ & $24.9 \pm 5.11$ & $47.9 \pm 7.41$ \\
\hline Neostigmine & $52.3 \pm 4.08$ & $36.6 \pm 4.25$ & $70.1 \pm 6.89$ \\
\hline Magnolol (25mg/kg) & $49.8 \pm 6.40$ & $30.0 \pm 4.29^{\star *}$ & $60.3 \pm 5.17^{\# \#^{\star}}$ \\
\hline Magnolol $(50 \mathrm{mg} / \mathrm{kg})$ & $47.7 \pm 5.33$ & $28.5 \pm 5.30^{\star \star \star}$ & $59.6 \pm 7.66^{\# \#^{* \star}}$ \\
\hline Magnolol $(100 \mathrm{mg} / \mathrm{kg})$ & $47.5 \pm 4.62$ & $25.6 \pm 3.50^{\star \star \star}$ & $54.1 \pm 7.27^{\star \star \star}$ \\
\hline
\end{tabular}

\section{Effect of magnolol on small intestinal transit}

There were no significant differences in small intestine length among the groups (Table 2); however, neostigmine group had higher $(p<$ 0.01) carbon promotion distance than the magnolol groups. Under normal conditions, the SIT rate of the charcoal meal was $47.88 \pm 7.41$ $\%$. Neostigmine increased SIT by about $46 \%$ over that of normal control group. After administration of magnolol (25, 50, and 100 $\mathrm{mg} / \mathrm{kg}$ ), SIT rate decreased to $60.34 \pm 5.17$, $59.61 \pm 7.66$, and $54.12 \pm 7.27 \%$ in the magnolol groups, respectively, as compared with neostigmine group. Administration of magnolol suppressed the SIT induced by neostigmine in a dose-dependent manner.

\section{Effect of magnolol on activity of blood antioxidation enzymes}

The activities (U/mg prot) of CAT, GSH-PX and T-SOD of mice gavaged with different doses of magnolols were all higher $(p<0.001)$ than those of normal control mice (Fig 1). Mice treated with magnolol had higher GSH-PX $(p<0.001)$ activities than positive control mice.

\section{Effect of magnolol on liver antioxidation status}

Normal control mice had lower $(p<0.01)$ CAT activities than magnolol-gavaged mice, which in turn showed higher CAT activity than positive control mice (Table 3). Mice gavaged with different doses of magnolols had higher T-SOD activity $(p<0.001)$ than normal control mice. Magnolol $(25 \mathrm{mg} / \mathrm{ml})$ mice had lower $(p<0.01)$ GSH-PX activity than positive control mice, while magnolol $(100 \mathrm{mg} / \mathrm{ml})$ mice had higher $(p<0.05)$ GSH-PX activity than normal control mice. GSH of normal control mice was lower $(p<0.05)$ than that of mice treated with a high dose of magnolol $(100 \mathrm{mg} / \mathrm{kg})$. Normal control mice had lower $(p<$ $0.01)$ T-AOC than all magnolol groups. Magnolol (50 mg/kg) produced higher $(p<0.05)$ T-AOC than vitamin $\mathrm{E}$ group.

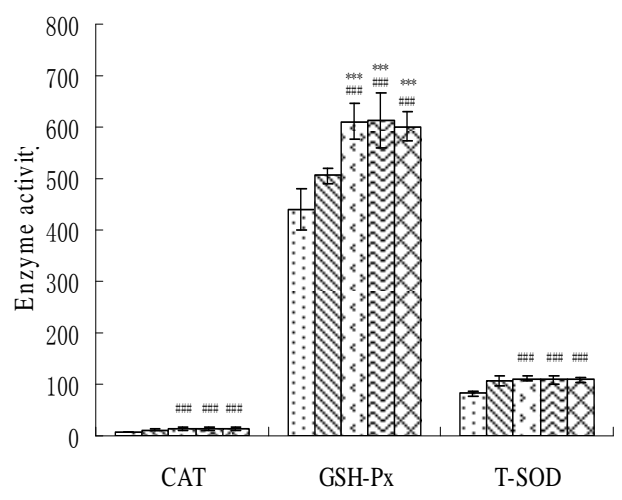

Fig 1. Effect of magnolol on activity of blood antioxidant enzymes in mice $(n=8)$.

Normal control $=$ normal saline; positive control $=$ vitamin $E ; \# p<0.05$, \#\#p < 0.01, \#\#\#p < 0.001, compared with normal control; ${ }^{*} p<0.05,{ }^{* *} p<$ $0.01,{ }^{* *} p<0.001$, compared with positive control : Normal control; NIII: Positive control; : Magnolol 25; 汽空: Magnolol 50; 登: Magnolol 100. 
Table 3: Effect of magnolol on liver antioxidant status in mice

\begin{tabular}{lccccc}
\hline Group & $\begin{array}{c}\text { CAT } \\
\text { (U/mg prot) }\end{array}$ & $\begin{array}{c}\text { T-SOD } \\
\text { (U/mg prot) }\end{array}$ & $\begin{array}{c}\text { GSH-Px } \\
\text { (U/mg prot) }\end{array}$ & $\begin{array}{c}\text { GSH } \\
\text { (mg/mg prot) }\end{array}$ & $\begin{array}{c}\text { T-AOC } \\
\text { (U/mg prot) }\end{array}$ \\
\hline Normal control & $7.73 \pm 1.31$ & $44.3 \pm 4.77$ & $167.6 \pm 13.06$ & $0.79 \pm 0.07$ & $0.60 \pm 0.09$ \\
Positive control & $10.19 \pm 1.25$ & $56.9 \pm 4.97$ & $201.3 \pm 14.84$ & $0.89 \pm 0.09$ & $0.72 \pm 0.08$ \\
Magnolol (25mg/kg) & $13.14 \pm 2.36^{\# \#}$ & $54.5 \pm 2.70^{\# \# \#}$ & $174.6 \pm 19.50^{* \star}$ & $0.84 \pm 0.16$ & $0.87 \pm 0.13^{\# \#}$ \\
Magnolol (50mg/kg) & $15.36 \pm 4.83^{\# \# \#^{* *}}$ & $54.7 \pm 5.05^{\# \# \#}$ & $185.8 \pm 7.01$ & $0.86 \pm 0.10$ & $0.93 \pm 0.13^{\# \# \#^{*}}$ \\
Magnolol (100mg/kg) & $17.02 \pm 3.81^{\# \# \#^{* \star}}$ & $54.9 \pm 5.84^{\# \# \#}$ & $189.7 \pm 13.61^{\#}$ & $1.01 \pm 0.27^{\#}$ & $0.92 \pm 0.23^{\# \# \#}$ \\
\hline
\end{tabular}

Normal control = normal saline; positive control = vitamin $E ; \# p<0.05$, \#\#p $<0.01$, \#\#p $<0.001$, compared with normal control; * $p<0.05,{ }^{* *} p<0.01,{ }^{* *} p<0.001$, compared with positive control

Table 4: Effect of magnolol on gene expression of anti-oxidant enzymes in liver $(n=8)$

\begin{tabular}{|c|c|c|c|c|c|}
\hline Groups & CAT & GSH-Px & $\mathrm{Cu} / \mathrm{Zn}-\mathrm{SOD}$ & Mn-SOD & EC-SOD \\
\hline Normal control & $0.32 \pm 0.02$ & $4.49 \pm 0.69$ & $1.28 \pm 0.19$ & $0.060 \pm 0.015$ & $0.002 \pm 0.0011$ \\
\hline Positive control & $0.42 \pm 0.06$ & $7.08 \pm 0.56$ & $1.55 \pm 0.14$ & $0.074 \pm 0.018$ & $0.002 \pm 0.0010$ \\
\hline Magnolol 25 & $0.43 \pm 0.08$ & $4.76 \pm 0.75^{* * *}$ & $1.39 \pm 0.29$ & $0.055 \pm 0.009$ & $0.005 \pm 0.0016^{\# \#^{* *}}$ \\
\hline Magnolol 50 & $0.60 \pm 0.08^{\# \# \# * *}$ & $4.86 \pm 0.30^{* * *}$ & $1.33 \pm 0.17$ & $0.064 \pm 0.014$ & $0.006 \pm 0.0014^{\# \# \# * * *}$ \\
\hline Magnolol 100 & $0.61 \pm 0.06^{\# \# \# * *}$ & $4.87 \pm 0.68^{* * *}$ & $1.51 \pm 0.18$ & $0.065 \pm 0.013$ & $0.004 \pm 0.0015$ \\
\hline
\end{tabular}

Normal control = normal saline; positive control = vitamin E; \#p < 0.05, \#\#p < 0.01, \#\#\#p<0.001, compared with normal control; ${ }^{*} p<0.05,{ }^{* *} p<0.01,{ }^{* *} p<0.001$, compared with positive control.

\section{Effect of magnolol on gene expression of anti-oxidant enzymes in liver}

CAT had higher gene expression level (Table 4) in mice gavaged with magnolol than in normal control $(p<0.001)$ and positive control mice $(p<$ 0.01 ). Mice treated with different doses of magnolols had higher $(p<0.001)$ GSH-PX gene expression than positive control mice. Gene expression of $\mathrm{Cu} / \mathrm{Zn}-\mathrm{SOD}$ and $\mathrm{Mn}-\mathrm{SOD}$ did not differ among groups. Though expression of ECSOD in all groups was very low, mice gavaged with lower doses of magnolol (25 and $50 \mathrm{mg} / \mathrm{kg}$ ) had higher $(p<0.01)$ EC-SOD expression level than normal control and positive control mice.

\section{DISCUSSION}

Castor oil-induced diarrhea is as a result of the action of ricinoleic acid formed from the hydrolysis of its triglyceride in the duodenum by pancreatic lipase. The ricinoleic acid produces irritation and inflammation of the intestinal mucosa and also stimulates intestinal hypermotility and hypersecretion. These series of action lead to diarrhea after the administration of castor oil $[13,14]$. The fact that the extract exhibited inhibitory effect against the castor oilinduced diarrhea implies that this property could contribute to the anti-inflammatory, antihypermotility or anti-hypersecretion activities of the plant.
In some previous studies, magnolol was found to exhibit anti-inflammatory activities. Wang et al observed that magnolol inhibited mouse hindpaw oedema induced by carrageenan and polymyxin $B$, and reversed passive Arthus reaction, and it was proposed that the antiinflammatory and analgesic action of magnolol is dependent on reducing the level of eicosanoid mediators[15]. An inhibitory action of magnolol on the production of leukotriene (LT) C4 and LTB4, important lipid mediators in allergy and inflammation was observed in basophilic leukemia (RBL)-2H3 cells of intact rat [16]. It was also found that magnolol inhibits TNF- $\alpha$-induced nuclear translocation of NF-KB p65 and thereby suppresses expression of VCAM-1, resulting in reduced adhesion of leukocytes [17]. These data suggest that magnolol acts as a potent antiinflammatory agent both in vitro and in vivo.

Magnolol has been found to have muscle relaxing effect. Teng et al reported that magnolol relaxed vascular smooth muscle in rat thoracic aorta [18] and Ko et al found magnolol had inhibitory actions on smooth muscle contraction in porcine trachea [19]. Recent research showed magnolol reduced vascular contraction by inhibiting the RhoARho kinase pathway in endothelium-denuded rat aorta [20]. In this study, magnolol significantly reduced hyperactive intestinal transit induced by neostigmine, which might be related with their possible relaxing effect on mouse intestinal smooth muscle. Furthermore, acetylcholine stimulates 
gastrointestinal motility and neostigmine is an inhibitor of acetylcholinesterase (AChE) which metabolizes acetylcholine to inactive metabolites. By enhancing enteric acetylcholine, neostigmine exerts gastrointestinal motility stimulating action. This suggests that the inhibition of neostigmineinduced hyper-intestinal movement is possibly related to the effect of magnolol upon acetylcholine system in small intestine; this possibility needs to be studied further.

Diarrhea occurs when bowel contents are passed without being sufficiently digested or absorbed due to accelerated enteric juice secretion or peristalsis after stimulation of the enteric tract [21]. Therefore, although there might be other mechanisms for inhibiting diarrhea and further investigations are necessary, one reason for the anti-diarrhea effect of magnolol may be due to the inhibition of excessively accelerated movement of the small intestine.

In addition, Bian et al indicated that magnolol can inhibit the contraction of isolated colonic muscle strips in Guinea pig by blocking the voltage dependent calcium channel and inhibiting calcium release from the sarcolemmal membrane [22]. Consequently, magnolol may be considered a putative calcium antagonist or calcium channel blocker. Calcium is involved in secretory diarrhea by modulating secretion of chloride or potassium, and gut motility also seems to be mediated by calcium flux [23]. As calcium antagonism, magnolol could be speculated to have both anti-motility and antisecretory effects, which might be helpful in inhibiting diarrhea. Taken as a whole, the antidiarrheal activity of magnolol may be an integration of multi-mechanisms.

The changes in antioxidant enzyme activities can reflect the anti oxidation status in animal. In this study, CAT, GSH-Px and SOD activities in the blood plasma and liver of Kunming mice significantly increased by treatment with magnolol, suggesting that they could provide more powerful antioxidant protection. On the other hand, treatment with magnonlol caused a remarkable increase in the gene-expression levels of CAT and EC-SOD. At the same time the gene expression levels of GSH-Px and CuZnSOD in magnolol-treated mice were higher than that in normal control mice. Therefore, administration of magnolol to Kuming mice induced the increment in CAT, GSH-Px and TSOD activities possibly by up-regulating the gene-expression level of CAT, GSH-Px and TSOD, which being ascribed to the antioxidant action of magnolol.
Tissue GSH plays a central role in antioxidant defense by detoxifying ROS directly or in a GSHPx catalyzed mechanism. Magnolol has been found to have a protective effect against Dgalactosamine-induced hepatotoxicity, which was used as an alternate model to oxidative stress, acting by inhibiting intracellular GSH depletion [24]. Our present study also showed magnolol increased GSH of normal mice liver. This increase in the GSH level may be due to an increased antioxidant capacity of liver and body.

Total antioxidant capacity (T-AOC) reflects the capacity of the non-enzymatic antioxidant defense system. In this study, magnolol administration greatly elevated the total antioxidant capacity in the livers. Magnolol treatment at a dose of $50 \mathrm{mg} / \mathrm{kg}$ had the highest increase in total antioxidant capacity in all tested groups. Above results showed that magnolol might increase the activities of both the nonenzymatic and enzymatic antioxidant defense systems and have a good potential to be used as natural antioxidant.

\section{CONCLUSION}

The present results have shown that magnolol of Cortex Magnolia Officinalis possesses antidiarrheal and anti-oxidation activities. Further studies, however are needed to identify its precise mechanism of action.

\section{ACKNOWLEDGEMENTS}

The authors wish to express their sincere gratitude and appreciation to the National Natural Science Foundation of China (Grant no. 30972166), Hunan Provincial Education Department (Grant no. 08A031) and Ministry of Science and Technology (Grant no. 2007DFA31360) for providing financial support for this study.

\section{REFERENCES}

1. Chen G, Xu X, Zhu Y, Zhang L, Yang $P$. Determination of honokiol and magnolol in cortex Magnoliae Officinalis by capillary electrophoresis with electrochemical detection. J Pharmaceut Biomed 2006; 41: 14791484.

2. Chan LW, Cheah EL, Saw CL, Weng W, Heng PW. Antimicrobial and antioxidant activities of Cortex Magnoliae Officinalis and some other medicinal plants commonly used in South-East Asia. Chinese Med 2008; 3: 15.

3. Lei ZQ. The Chinese Materia Medica. 1 ed. Shanghai: Shanghai Science and Technology Press; 1995.

4. Ikeda K, Sakai $Y$, Nagase H. Inhibitory effect of magnolol on tumour metastasis in mice. Phytother Res 2003; 17: 933-937.

5. Ho KY, Tsai CC, Chen CP, Huang JS, Lin CC, Antimicrobial activity of honokiol and magnolol 
isolated from Magnolia officinalis. Phytother Res 2001; 15(2): 139-141.

6. Saito J, Shibuya K, Nagase H. Anti-clastogenic effect of magnolol on benzo[a]pyrene-induced clastogenicity in mice. Food Chem Toxicol 2008; 46: 694-700.

7. Pyo MK, Lee Y, Yun-Choi HS. Anti-platelet effect of the constituents isolated from the barks and fruits of Magnolia obovata. Arch Pharm Res 2002; 25: 325 328.

8. Kuo DH, Tsai SW, Pan MH. Magnolol blocks homocysteine-induced endothelial dysfunction in porcine coronary arteries. Food Chem 2011; 127: 135-140.

9. Chinese Association For Laboratory Animal Sciences. Guidelines to Good Practice in Laboratory Animals Feeding and Management. 2009.

10. Islam M, Barua J, Karon B, Noor M. Antimicrobial, cytotoxic and antidiarrhoeal activity of Fimbristylis aphylla L. Int J Green Pharm

11. Zhou GN, Hu ZH, Wang $Y X$, Zhang KB. An inquiry into preparing diarrhea model of mice and application of diarrhea index. Chin Tradit Herbal Drugs 1999; 25(4): 195-196.

12. Peddyreddy MK, Dkhar SA, Ramaswamy S, Naveen AT, Shewade DG. An inherent acceleratory effect of insulin on small intestinal transit and its pharmacological characterization in normal mice. World J Gastroenterol 2006; 12: 2593-2600.

13. Ammon PJ, Thomas, Philips S. Effects of oleic and recinoleic acids net jejunal water and electrolyte movement. J Clin Invest 1974; 53: 374-379.

14. Iwao I, Terada Y. On the mechanism of diarrhea due to castor oil. Jpn J Pharmacol 1962; 12: 137-145.15. Wang JP, Hsu MF, Raung SL, Chen CC, Kuo JS, Teng CM. Anti-inflammatory and analgesic effects of magnolol. Naunyn-Schmiedeberg's Arch. Pharm 1992; 346: 707-712.

16. Hamasaki $Y$, Kobayashi I, Zaitu M, Tsuji K, Kita M, Hayasaki $R$, Muro E, Yamamoto S, Matsuo M, Ichimaru T, Miyazaki S. Magnolol Inhibits Leukotriene
Synthesis in Rat Basophilic Leukemia-2H3 Cells. Planta Med 1999; 65(3): 222-226.

17. Chen YH, Lin SJ, Chen JW, Ku HH, Chen YL. Magnolol attenuates VCAM-1 expression in vitro in TNF-alphatreated human aortic endothelial cells and in vivo in the aorta of cholesterol-fed rabbits. Br J Pharmacol 2002; 135(1): 37-47.

18. Teng CM, Yu SM, Chen CC Huang $Y L$, Huang TF. EDRF-release and $\mathrm{Ca}^{[++]}$-channel blockade by magnolol, an antiplatelet agent isolated from Chinese herb Magnolia officinalis, in rat thoracic aorta. Life Sci 1990; 47: 1153-1161.

19. Ko $\mathrm{CH}$, Chen $\mathrm{HH}$, Lin YR, Chan $\mathrm{MH}$. Inhibition of smooth muscle contraction by magnolol and honokiol in porcine trachea. Planta Med 2003; 69: 532-536.

20. Seok YM, Kim HY, Garmaa O, Cha BY, Woo JT, Kim IK. Effects of magnolol on vascular contraction in rat aortic rings. Clin Exp Pharmacol Physiol 2012; 39(1): 28-36.

21. Saitoh $K$, Kase $Y$, Ishige $A$, Komatsu $Y$, Sasaki $H$, Shibahara N. Effects of Keishi-ka-shakuyaku-to (GuiZhi-Jia-Shao-Yao-Tang) on diarrhea and small intestinal movement. Biol Pharm Bull 1999; 22(1): 8789.

22. Bian ZX, Zhang GS, Wong KL, Hu XG, Liu L, Yang Z, Li $M$. Inhibitory effects of magnolol on distal colon of guinea pig in vitro. Biol Pharm Bull 2006; 29(4): 790795.

23. Irie K, Yoshioka T, Nakai A, Ochiai K, Nishikori T, Wu GR, Shibuya H, Muraki T. A Ca(2+) channel blockerlike effect of dehydrocurdione on rodent intestinal and vascular smooth muscle. Eur J Pharmacol 2000; 403: 235-242.

24. Park EJ, Zhao YZ, Na M, Bae K, Kim YH, Lee BH, Sohn $D H$. Protective effects of honokiol and magnolol on tertiary butyl hydroperoxide- or D-galactosamineinduced toxicity in rat primary hepatocytes. Planta Med 2003; 69(1): 33-37. 